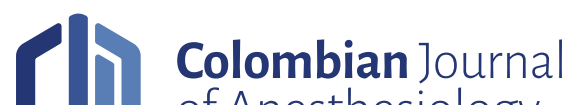 \\ of Anesthesiology
}

\section{Use of MeNTS, Frailty and Symptom Scales for selecting surgical patients during the SARS-CoV-2 pandemic: A retrospective study}

\section{Uso de escalas MeNTS, Fragilidad y Síntomas para la selección de pacientes quirúrgicos durante la pandemia por SARS-CoV-2: Estudio retrospectivo}

Luis Alberto Tafur Betancourt ${ }^{\mathrm{acc}}\left(\mathbb{D}\right.$, Adriana Sofía Rosero Cundar ${ }^{\mathrm{b}}$ (D), Sergio Andrés Remolina Granados ${ }^{\mathrm{d}}$ (D), Marcela Arévaloe, (D), María del Mar Millán G. e,g (iD), Eduardo Lema Flórez ${ }^{\mathrm{h}}$ (D), Andrés Zorrilla Vaca ${ }^{\mathrm{h}}$ (D), Víctor Hernán Ruiz Holguín ${ }^{\mathrm{b}}$, Catalina Ceballos ${ }^{\mathrm{b}}$ (D), Jaime Quintero Soto ${ }^{\mathrm{d}}$

a Plataforma de seguridad Seganest. Cali, Colombia.

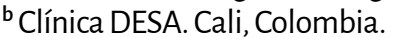

'Instituto para Niños Ciegos y Sordos. Cali, Colombia.

${ }^{d}$ Consorcio Nueva Clínica Rafael Uribe Uribe. Cali, Colombia.

e Universidad Libre. Cali, Colombia.

f Universidad Surcolombiana. Cali, Colombia.

' Universidad Militar Nueva Granada. Bogotá, Colombia.

h Universidad del Valle. Cali, Colombia.

Correspondence: Calle 5B2 \# 37 ${ }^{\mathrm{a}}$-50. Cali, Colombia. E-mail: luis.tafur@seganest.com

\section{Abstract}

What do we know about this issue?

The SARS-CoV-2 pandemic has led to the cancellation of non-emergent surgeries in order to optimize the use of resources. Once the elective medical services are restored, it becomes critical to have a technical and ethical strategy to select candidate patients for elective surgery.

Therefore, there is a need to consider factors that were previously disregarded, such as the risk of SARS-CoV-2 infection in non-infected patients who will undergo an elective surgical procedure.

What new contributions are made by this study?

The administration of the MeNTS scale, FI-CCA and the Symptoms Survey are easy to access methods amidst the pandemic and are helpful to select patients with an intermediate and low risk of perioperative morbidity in elective surgery during the SARS-CoV-2 pandemic

\section{How to cite this article:}

Tafur Betancourt LA, Rosero Cundar AS, Remolina Cranados SA, Arévalo M, Millán C. $M$ del M, Lema Flórez E, et al. Use of MeNTS,

Frailty and Symptom Scales for selecting surgical patients during the SARS-CoV-2 pandemic: A retrospective study Colombian Journal of Anesthesiology. 2022;50:e999.
Introduction: The SARS-CoV-2 pandemic has led to the cancellation of non-emergent surgeries in order to optimize the use of resources. Once the elective medical services are restored, a technical and ethical strategy becomes critical to select candidate patients for elective surgery.

Objective: To describe the results from the implementation of MeNTS (Medically Necessary Timesensitive Procedures), Fl-CCA, and survey on COVID-19 symptoms Scales, as methods for the selection of patients who were candidates for elective surgery during the SARS-CoV-2 pandemic, in a third level institution in Cali, Colombia.

Methods: The databases of the results on the administration of MeNTS, frailty index (FI-CCA) and COVID 19 symptoms scales in patients who were candidates for elective surgery in a third level clinic in Cali city, between March 1st and August 31st, 2020 were reviewed.

Results: A total of 1,044 patients were included, of which 647 (62.0\%) were females, with a median age of 52 years (interquartile range [IQR] $38-62$ ). $98 \%$ of the patients were asymptomatic, the overall median score for MeNTS was 48 (IQR 44-52) and the average for Fl-CCA was 0.0 (standard deviation 0.1).

Conclusions: MeNTS, FI-CCA and the Symptoms Survey are easily accessible scales amidst the pandemic and are helpful to select patients with intermediate and low risk of perioperative morbidity in elective surgery during the SARS-CoV-2 pandemic. Further studies are required to confirm these findings and to clarify the potential of these tools in the selection of patients that meet the high-risk criteria.

Keywords: Outpatient surgical procedures; Risk behavior; SARS-COV-2 infection; Risk scales; Anesthesiology. 


\section{Resumen}

Introducción: La pandemia por SARS-CoV-2 ha ocasionado la suspensión de cirugías no urgentes con el fin de optimizar los recursos. Una vez los servicios médicos electivos son restablecidos, es fundamental disponer de una estrategia técnica y ética para la selección de los pacientes candidatos a cirugía electiva.

Objetivo: Describir los resultados observados durante la implementación de las escalas MeNTS (Medically Necessary Time-sensitive Procedures), IF-VIC y Encuesta de síntomas para COVID-19, como métodos de selección de pacientes candidatos a cirugía electiva durante la pandemia por SARS-CoV-2 en una institución de nivel tres en la ciudad de Cali, Colombia.

Metodología: Se revisaron las bases de datos de los resultados de la aplicación de escalas de MeNTS, índice de fragilidad (IF-VIC) y los síntomas para COVID 19, en pacientes candidatos a cirugía electiva en una clínica de tercer nivel en la ciudad de Cali, entre marzo 1 y agosto 31 del 2020.

Resultados: En total 1.044 pacientes fueron incluidos, de los cuales 647 (62,0\%) fueron mujeres con una mediana de edad de 52 años (rango intercuartil [RIC] 38-62). El $98 \%$ de los pacientes estuvieron asintomáticos, la mediana general de la puntuación total de MeNTS fue 48 (RIC 44-52) y el promedio para IF-VIC fue de 0,0 (desviación estándar 0,1).

Conclusiones: MeNTS, IF-VIC y Encuesta de síntomas, son escalas fácilmente accesibles durante tiempos de pandemia y son de utilidad para seleccionar pacientes de riesgo intermedio y bajo de morbilidad perioperatoria en cirugía electiva durante la pandemia por SARS-CoV-2. Se requieren futuros estudios para confirmar estos hallazgos y para clarificar su potencial en la selección de pacientes con criterios que los definan como de riesgo alto.

Palabras clave: Procedimientos quirúrgicos ambulatorios; Comportamiento del riesgo; Infección por SARS-COV-2; Escalas de riesgo; Anestesiología.

\section{INTRODUCTION}

During the SARS-CoV-2 pandemic, the number of non-emergent surgeries was drastically reduced, due to the need to reallocate healthcare resources to meet massive needs. (1). Moreover, the rapid spread of SARS-CoV-2 (COVID-19) infection has further intensified the health crisis worldwide (2). In Colombia, the so called COVID-19 disease, has concentrated in the more densely populated areas. In Valle del Cauca, the mortality rate has been one of the highest in the country, reaching levels as high as $6.38 \%$ and 4.44 $\%$, in cities such as Buenaventura and Cali, respectively (3). This situation lead to the cancellation of elective surgical procedures in most hospitals, for fear of increasing both morbidity and mortality (4).

In order to make the decision to restore elective medical services, it is essential to define the optimal moment to select patients and move forward to reopen this service. Therefore, it is necessary to consider factors previously disregarded $(5,6)$,such as the risk of SARS-CoV-2 infection in non- infected patients that will undergo an elective surgery (6).

The recommendations based on the best available evidence to date establish the guiding principles for the resumption of elective surgeries as a strategy to mitigate the impact of the restrictive measures (7). One of those principles focuses on patient selection, in cases where time may be critical (Figure 1). Moreover, the American College of Surgery (ACS) approved a system to prioritize surgeries called MeNTS (Medically Necessary Time Sensitive procedures), to select the time-sensitive elective procedures $(1)$. In addition to this tool which identifies the patient at low risk of infection, low requirement of hospital resources and low risk medical condition, it is critical to assess the level of vulnerability in an increasingly aging population.

In Colombia, between 1995 and 2000 the population over 60 years old increased in proportion and has been maintained over the following decades (8). During the COVID-19 pandemic, the elderly have been particularly vulnerable (9). Jhonatan et al., studied the impact of frailty on the survival of the elderly with COVID-19, and found that it was associated with both early death and longer hospital stay (10). The most widely used tool to quantify frailty is the fragility index comprehensive geriatric assessment tool (FI-CGA). According to this scale, scores below 0.2 are associated with a o \% mortality at 12 months, while a FI-CGA of 0.64 is associated with a $100 \%$ mortality at 12 months $(11)$.

Designing scales such as MeNTS and Frailty is a key strategy for an ethical and technical selection of elective patients who are in the waiting list to undergo surgery. Currently these are the only tools available to make a decision, since the term elective is not a synonym of optional in these surgeries; hence, some institutions have used these tools as a strategy to resume their activities.

Another indispensable variable when selecting patients for elective procedures is the likelihood of having COVID-19. It has been observed that COVID-19 symptoms are similar to those of flu; however, a combination of the most predictive symptoms could help to 
FIGURE 1. Steps established by the Joint Statement for resumption of outpatient procedures.

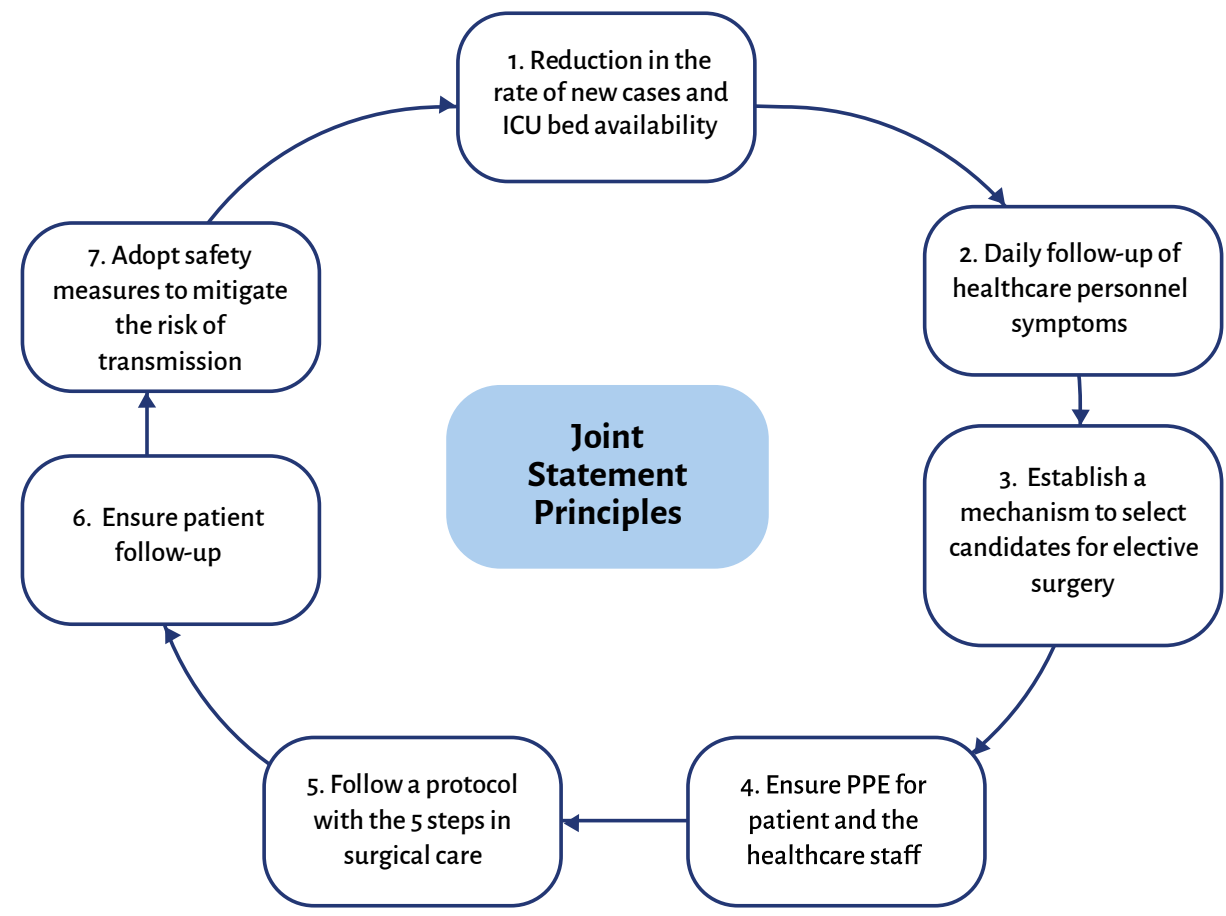

SOURCE: Authors.

guide the diagnosis of SARS-CoV-2 (12). Based on the WHO recommendations, the Ministry of Health has standardized the case definition for SARS-CoV-2/ COVID-19 infection. Such definition, pursuant to epidemiological and clinical criteria, establishes three types of cases: suspicious, probable and confirmed.

The objective of this study is to describe the results of the implementation of the MeNTS, FI-CCA and the COVID-19 Symptoms Survey Scales, as selection methods of patients who are candidates for elective surgery amidst the SARS-CoV-2 pandemic.

\section{METHODOLOGY}

\section{Design and study population}

This retrospective study was designed using the medical registry of patients candidates for elective surgery in a third level clinic in Cali, during the COVID-19 pandemic, between March 1st and August 31st, 2020. The elective cases were defined as those in which a reasonable delay could be acceptable; the procedures that were not an emergency, but were time-critical, were fast-tracked and were not included in this initiative. The study was endorsed by the ethics committee of the institutions involved, pursuant to Minutes INV-01-2021 and each participant gave his/her informed consent.

\section{Inclusion Criteria}

The patients included were between 18 and 70 years old, candidates to elective surgery who met the cut-off points of the scales selected (MeNTS, FI-CCA and Symptoms Survey) for assessment, and had a negative COVID-19 RT-PCR test prior to surgery.

\section{Exclusion Criteria}

The patients excluded were: pregnant women, patients who refused surgery, and those who while waiting for the surgical procedure, became infected with COVID-19
- confirmed with a molecular RT-PCR test and those who failed to submit the results of the COVID-19 RT-PCR before surgery.

\section{Collection of Information}

The databases with the results of the scores were reviewed to prioritize surgeries: MeNTS, FI-CCA and symptoms Survey, and these were uploaded into the MyChecktime ${ }^{\circledR}$ software (a program developed for enhanced operating room safety) (13).

The cut-off points for the assessment scales were taken from the current recommendations for each scale.

\section{MeNTS Scale}

The American College of Surgeons (ACS) suggests that patients should undergo ambulatory surgery during the pandemic with a score below 57 points (7); other organizations such as the Spanish Association of Surgeons recommends a score of 60 points, which is accepted by the Colombian Association of Surgeons (5). The MeNTS score is estimated in each case based on 21 different items, including procedure factors, disease factors, and factors particular to the patient; the scores range from 21 to 105. Low scores suggest a higher priority, less use of resources and lower risk for the patient (8). The cut-off point used by the institution was less than 60 points.

\section{Frailty Index}

Before the pandemic, Jordi Amblàs-Novellas et al. documented that scores below 0.2 were associated with a $0 \%$ mortality at 12 months, and a FI-CCA of 0.64 was associated with a $100 \%$ mortality at 12 months. In order to avoid adding a risk factor, the cutoff point for patients undergoing surgery in this institution was 0.2 (11). 


\section{Probability of COVID-19 based on symptoms}

Based on a survey, the institution considered the asymptomatic patients; i.e., patients with no clinical or epidemiological criteria according to $\mathrm{WHO}$, to define a suspicious, probable or confirmed case of SARS-CoV-2.

\section{Administration of the assessment scales: MeNTS, FI-CGA and SARS-CoV-2- associated Symptoms Survey}

At the institution, the surgeon and the anesthesiologist together, via teleconsultation, administered the MeNTS, FICCA and SARS-CoV-2 - related symptoms survey. This information was used to populate the repository of surveys or databases. The patients programmed by the institution were those who met the cutoff points in the assessment scales.

Additionally, the patients who met the cut-off points underwent a molecular PCR test prior to the procedure. All patients who were candidates for elective surgery, had a teleconsultation to assess whether they presented clinical or epidemiological criteria for SARS-CoV-2 suspicion.

\section{STATISTICAL ANALYSIS}

The data for the statistical analysis were obtained from the information exported from the database of the MyChecktime ${ }^{\circledast}$ software to an Excel spreadsheet. The continuous variables are expressed as average, standard deviation or median and interquartile range, based on the assumption of a normal distribution of the data. The categorical variables were described with frequencies and proportions. The data analysis used the statistical software Stata 14 (StataCorp, College Station, TX).

\section{RESULTS}

Between March 1st and August 31st, 2020, from a database of 1,800 patients waiting for ambulatory surgery, the institution selected 1,044 patients less than 70 years old and administered the surgical prioritization scales (MeNTS, FI-CGA and COVID Symptoms) via teleconsultation. The median age was 52 years (IQR 38-62), of which $647(62.0 \%)$ were females and 397 $(38.0 \%)$ were males. The medical specialties most frequently waiting for surgery were urology, 151 (14.5\%); orthopedics, 132 (12.6\%); gastroenterology, 116 (11.1 $\%)$; dermatology, 107 (10,2\%); general surgery, 100 (9.6\%) and gynecology, 95 (9.1\%). The medianprobability of symptoms for COVID-19 was 15 (IQR 1515), the overall median of the total MeNTS score was 48 (IQR 44-52) and the average for FI-CCA was 0.0 (SD 0.1) (Tables $1 \& 2$ ).

Of the 1,044 patients programmed for elective surgery, the institution selected 992 who met the cut-off points. However, the molecular RT-PCR test for COVID-19 was only available for 343 of these patients, with 16 patients who tested positive and 327 negative. During the selection process, 579 individuals were lost due to the nonavailability of molecular RT-PCR tests during the peak of the pandemic (Figure 2). With regards to the analysis of central trend measurements of the 327 patients with negative PCR, the median age was 51 years (IQR 38-61), of which 207 (63.3\%) were females and 120 (36.7\%) were males. The most common surgical procedures were in the following specialties: $\mathrm{OB} /$ CYN, 91 (28\%); orthopedics, 64 (19.6\%) and urology, 49 (15.0\%). Ambulatory procedures were classified based on the surgical risk: 40 (12.2\%) were high risk (for instance, joint replacements); 108 (33 $\%)$ intermediate risk (for instance intraabdominal surgeries) and 155 (47.4\%) low

TABLE 1. Outpatients (by gender and specialty) who were administered the MeNTS, FI-CCA and Symptoms Scales.

\begin{tabular}{|c|c|}
\hline Characteristic & $n=1,044(\%)$ \\
\hline Age (years) & $52(38-62)$ \\
\hline \multicolumn{2}{|l|}{ Gender* } \\
\hline Male & $397(38.0)$ \\
\hline Female & $647(62.0)$ \\
\hline \multicolumn{2}{|l|}{ Medical specialty* } \\
\hline Urology & $151(14.5)$ \\
\hline Orthopedics and traumatology & $132(12.6)$ \\
\hline Gastroenterology and endoscopy & $116(11.1)$ \\
\hline Dermatology & $107(10.2)$ \\
\hline General surgery & $100(9.6)$ \\
\hline Gynecology and obstetrics & $95(9.1)$ \\
\hline ENT & $70(6.7)$ \\
\hline Gynecology & $59(5.7)$ \\
\hline Maxillofacial surgery & $47(4.5)$ \\
\hline Plastic surgery & $39(3.7)$ \\
\hline Plastic and reconstructive surgery & $29(2.8)$ \\
\hline Other & $99(9.5)$ \\
\hline
\end{tabular}

SOURCE: Authors. 
TABLE 2. Outpatients who were administered the MeNTS, FI-CCA and Symptoms Scales.

\begin{tabular}{|c|c|}
\hline \multicolumn{2}{|c|}{ Characteristic } \\
\multicolumn{2}{|c|}{ Selection Scales } \\
\hline Symptoms for COVID-19 & \\
\hline Asymptomatic & $1,023(98.0)^{* *}$ \\
\hline MeNTS Score & $48(44-52)^{* * *}$ \\
\hline$<=60$ & $1,015(97.2)$ \\
\hline$>60$ & $29(2.8)^{*}$ \\
\hline FI-CGA & $0(0.1)^{*}$ \\
\hline$<=0.2$ & $1,021(97.8)^{*}$ \\
\hline$>0.2$ & $23(2.2)^{*}$ \\
\hline
\end{tabular}

*Average.

*** Median (IQR).

SOURCE: Authors.

TABLE 3. Patients with negative PCR who met the cut-off points of MeNTS $<60$, FI-CCA $<0.2$ and asymptomatic.

\begin{tabular}{|c|c|}
\hline Characteristic & $n=327(\%)$ \\
\hline Age (years) $* *$ & $51(38-61)$ \\
\hline \multicolumn{2}{|l|}{ Gender } \\
\hline Female & $207(63.3)$ \\
\hline Male & $120(36.7)$ \\
\hline \multicolumn{2}{|l|}{ Surgical specialty } \\
\hline OB/GYN & $91(28)$ \\
\hline Orthopedics & $64(19.6)$ \\
\hline Urology & 49 (15.0) \\
\hline Plastic surgery & $47(14.4)$ \\
\hline General surgery & $46(14.1)$ \\
\hline Others & $29(8.9)$ \\
\hline \multicolumn{2}{|l|}{ Surgical Risk } \\
\hline Very low risk & $24(7.3)$ \\
\hline Low risk & $155(47.4)$ \\
\hline Intermediate risk & $108(33.0)$ \\
\hline High risk & $40(12.2)$ \\
\hline \multicolumn{2}{|l|}{ Destination } \\
\hline Home & $243(74.3)$ \\
\hline Hospitalization & $82(25.1)$ \\
\hline ICU & $1(0.3)$ \\
\hline \multicolumn{2}{|l|}{ Hospital Stay (days) ${ }^{* * *}$} \\
\hline Hospitalization & $1(1-2)$ \\
\hline ICU & 2 \\
\hline COVID-19 symptoms two weeks POP* & $0(0.0)$ \\
\hline \multicolumn{2}{|l|}{ Discharge status two weeks POP* } \\
\hline Alive & $326(99.7)$ \\
\hline Death & $0(0.0)$ \\
\hline
\end{tabular}

*POP: postoperative.

** Median (IQR).

SOURCE: Authors. risk (for example, herniorrhaphies); only 23 (7\%) were classified as very low risk (for example, endoscopic procedures) (Table 3 ).

After surgery, one patient (0.3\%) was transferred to the ICU because of unstable angina and ventricular tachycardia, although acute myocardial infarction and pulmonary thromboembolism were ruled out; 82 (25.1\%) patients were hospitalized for postoperative management and 243 (74.3\%), were discharged. The median hospital stay was 1 day (IQR 1-2). During teleconsultation follow-up, according to the clinical records, there were no recorded COVID-19-associated complications or deaths two weeks after surgery (Table 3 ).

In terms of hospitalization, 7 patients were hospitalized for more than 2 days, with assessment scales within the cut-off points established and due to complications unrelated with COVID-19 (Table 4).

To conduct the surgical procedures, the institution engaged 200 workers including specialists, GPs, nursing staff and general services (housekeeping). By shift, approximately 45 people entered the surgical area in the morning, 45 in the afternoon and 10 in the evening. Over the study period and according to the information provided, only one case of COVID-19 was reported among the healthcare staff working in the ORs, but no epidemiological link was identified with the surgical microsystem.

\section{DISCUSSION}

The scoring systems for surgical prioritization such as those used in this study (MeNTS, FI-CGA and Symptoms) contribute with useful information for the selection of intermediate and low risk patients who are candidates for safe elective surgery in the context of the SARSCoV-2 pandemic $(8,14)$.

The negative health impact of adjourning medical-surgical procedures, in addition to the fact that the situation with the SARS-CoV-2 pandemic will not be resolved in the medium term, requires the 
TABLE 4. Characteristics of patients with a hospital stay longer than two days.

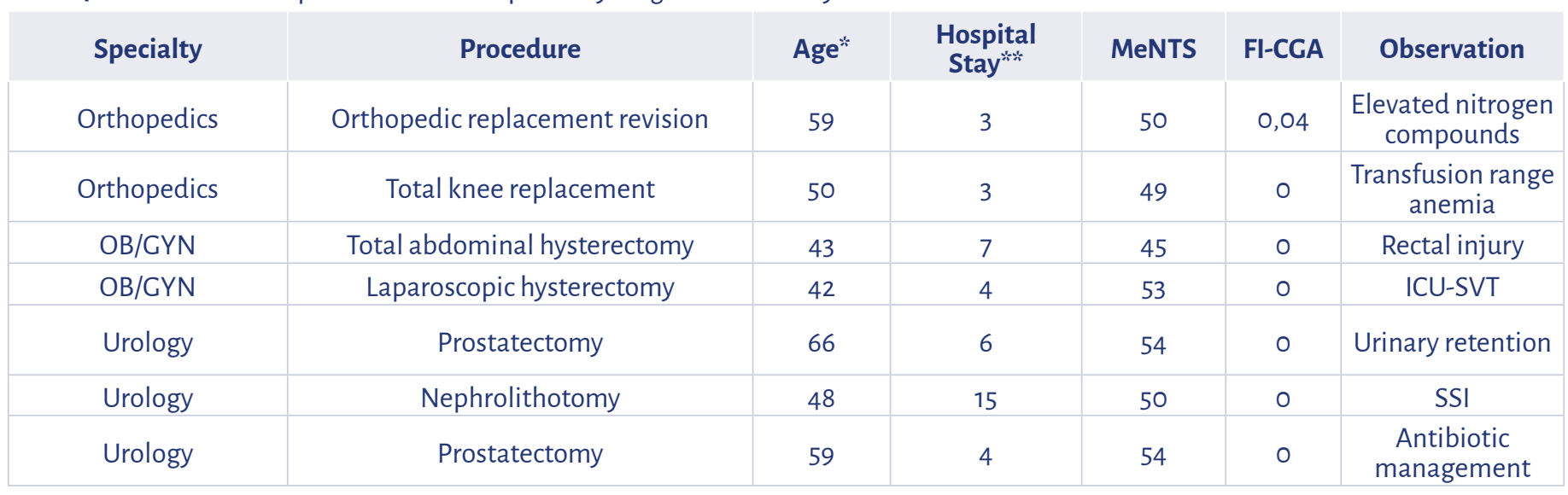

*Years; **days; ICU: intensive care unit; SVT: supraventricular tachycardia; SSI: surgical site infection; MeNTS: Medically Necessary Time Sensitive procedures; FI-CGA: frailty index.

SOURCE: Authors.

FIGURE 2. Patient selection flowchart.

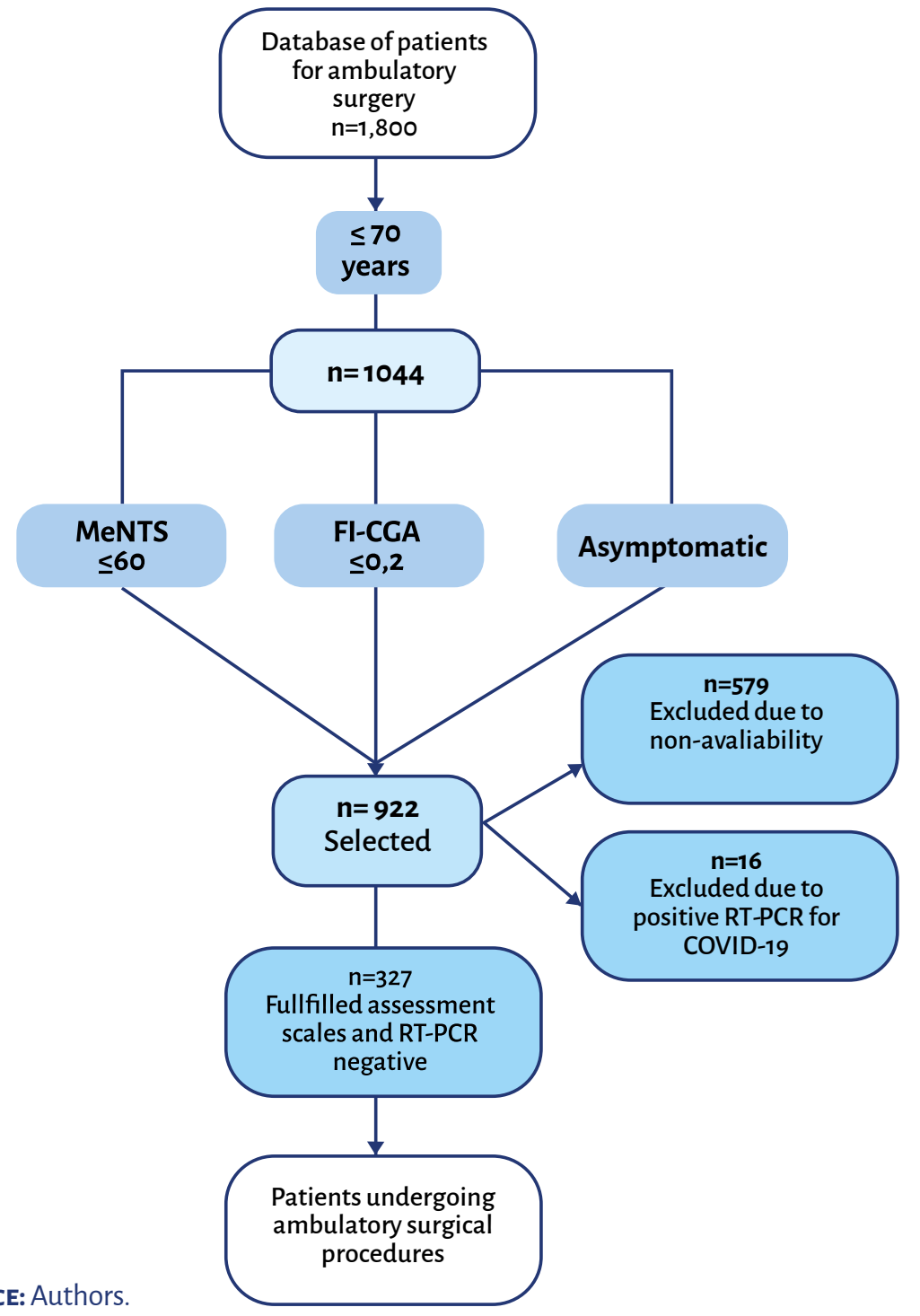

SOURCE: Authors resumption of care of patients that need procedures initially classified as elective and which were adjourned on the basis of increased morbidity and mortality risks (15). Therefore, it is critical to identify variables that provide information and facilitate the selection of procedures that can be performed safely $(16,17)$. One of the pillars in this process is the identification of SARS-CoV-2 infected individuals, in whom the procedure must be deferred. Several algorithms have been considered which involve serial diagnostic testing (RTPCR or detection of immunoglobulins) in addition to imaging studies, whether or not associated with predictive scales $\underline{(18)}$, which have not clearly shown a genuine impact.

The strategy assessed in this study is easy to administer and to reproduce in different institutions and allows for the identification of the lowest risk scenario for the surgical patient, taking into consideration the comorbidities, the procedure to be performed and the complexity involved; this is achieved through testing to identify pre-symptomatic and asymptomatic patients. Though there is limited information available on the impact of these strategies, they have proven to be effective in minimizing the risk of complications (18). In the Mayo Clinic, in an effort to reopen surgical procedures, the service of anesthesiology and neurosurgery adopted a similar sys- 
tem to that herein described, which consisted in conducting an epidemiological assessment of patients (Survey to identify clinical variables suggestive of COVID-19 in addition to exposure events) associated with diagnostic testing (RT-PCR) prior to surgery. Patients with negative results were programmed and the other patients were deferred until the isolation periods were completed or until viral infection was ruled out (except for emergent procedures). 103 patients were included and the assessment of the effects of this system in terms of infectious events and mortality; there were no documented cases of COVID-19-associated infection or postoperative deaths (19). Notwithstanding the various proposals, the evidence on approaches for selecting patients is limited, but it is necessary in the surgical environment.

The specific characteristics of the population insured, the number of COVID-19 cases at the time of the study, the geographical area and the risk of the procedures conducted, are all variables to keep in mind when determining the relevance of the strategy. This study was conducted in a population with a level of vulnerability above the national average, due to characteristics such as aging index, aging and old-age dependency $(20,167$ and 32 , respectively), far above the national average ( 7 , 27 and 11 for 2019) (20).

In addition to the risk associated with age-related vulnerability (21), it is important to highlight that the procedures conducted have a complexity risk consistent with the level of care; in other words, the risk of the surgical procedures conducted during the study period was classified as intermediate and high risk, $33 \%$ and $12 \%$, respectively.

Besides considering age and the risk of the procedures, another key factor to provide care to these patients during the pandemic was being able to ensure a short hospital stay to avoid increasing contagion and morbidity and mortality of the surgical population. In terms of length of hospital stay, this study showed that the percentage of postoperative hospitalization beyond 2 days was low and the follow-up after dis- charge did not report any deaths or potential SARS-CoV-2 infections.

One of the limitations of this study however, is that the results can only be extrapolated to intermediate risk populations and not to patients with a higher morbidity burden. This suggests the need to introduce a progressive change in the designated cut-off points in order to involve a larger number of patients with different characteristics to assess outcomes. Moreover, the strategy herein described is not infallible, since notwithstanding the control points established (care recommendations, use of diagnostic tests and implementation of the risk and detection scales), it is only possible to prevent OR admission to patients during the incubation period of COVID-19, but this will not prevent the infection; this is a potential risk to be considered by the entire healthcare team and by all patients. In order to improve effectiveness, the turnaround time of the results of the diagnostic tests should be quick, and this was an issue in the institution during the implementation of the strategy, because the laboratory was overwhelmed with the increasing demand for tests. Currently, in the case of institutions unable to provide adequate turnaround times for molecular tests, diagnostic antigen detection tests should be implemented, provided these have been validated in the country (22).

\section{CONCLUSION}

Instruments such as MeNTS, FI-CCA and Symptoms Survey are easily accessible during the pandemic and may be used to select patients with intermediate and low risk of perioperative morbidity undergoing elective surgery amidst the SARS-CoV-2 pandemic. Further studies are required to confirm these findings and to determine whether widening the selection ranges may help to identify the actual potential of the strategy of administering scales for the selection of patients exhibiting high risk criteria for perioperative morbidity amidst the current SARS-CoV-2 pandemic.

\section{ETHICAL DISCLOSURES}

\section{Ethics committee approval}

This study was approved by the Instituto para Niños Ciegos y Sordos del Valle del Cauca Ethics Committee, in a meeting held on February 1st, 2021, as recorded in act number INV-2021-001.

\section{Protection of human and animal subjects}

The authors declare that no experiments were performed on humans or animals for this study. The authors declare that the procedures followed were in accordance with the regulations of the relevant clinical research ethics commit-tee and with those of the Code of Ethics of the World Medical Association (Declaration of Helsinki).

\section{Confidentiality of data}

The authors declare that they have followed the protocols of their work center on the publication of patient data.

\section{Right to privacy and informed consent}

The authors declare that no patient data appear in this article.

The authors have obtained the written informed consent of the patients or subjects mentioned in the article. The corresponding author is in possession of this document.

\section{ACKNOWLEDGEMENT}

\section{Contributions by the authors}

LATB: Design of the initial idea, planning of the study, data collection supervision, interpretation of the results and follow-up of the initial draft of the manuscript and approval thereof. 
ASRC and ELF: Study planning, data collection supervision, interpretation of the results, development of the theoretical foundations for the initial manuscript.

SARG: Data collection supervision, interpretation of the results and data analysis.

MA and AZV: Search of information, construction and development of the initial manuscript, interpretation of the results.

MMMC: Drafting of the final manuscript, editing and development of schematics. Web platform format development.

VHRH: Collection and organization of the data required. Follow-up of cases and organization of medical records.

CC: Supervision of data collection, interpretation of the results.

JQS: Design of the initial concept. Data collection supervision, interpretation of the results.

\section{Assistance to the study}

None declared.

\section{Financial support and sponsorship}

None declared.

\section{Disclosures}

No conflict of interests to declare.

\section{Presentations}

None declared.

\section{Acknowledgments}

To the following organizations: Seguridad Médica Seganest SAS and Clínica Visual y Auditiva/Instituto para Niños Ciegos y Sordos (Cali).

\section{REFERENCES}

1. Zhu N, Zhang D, Wang W. A novel coronavirus from patients with pneumonia in China, 2019. N Engl ] Med. 2020;382:727-33. doi: https:// doi.org/10.1056/NEJMoa2001017

2. García-Perdomo HA, Beas-Sandoval LR. Teaching in academic and surgical programs in times of COVID-19 [La enseñanza en los programas académicos y quirúrgicos en tiempos de COVID-19]. Revista Mexicana de Urología. 2020;80(2):1-3. doi: https://doi.org/10.48193/ rmu.v80i2.622

3. Barrios A, Prieto R, Torregrosa L, Álvarez C, Hernández JD, Conzález LG, et al. Volver a empezar: cirugía electiva durante la pandemia del SARS-CoV2. Recomendaciones desde la Asociación Colombiana de Cirugía. Rev Colomb Cir. 2020;25(2):302-21. doi: https://doi. org/10.30944/20117582.656

4. Doglietto F, Vezzoli M, Gheza F, Lussardi CL, Domenicucci $M$, Vecchiarelli L, et al. Factors associated with surgical mortality and complications among patients with and without coronavirus disease 2019 (COVID-19) in Italy. JAMA Surg. 2020;155(8):1-14. doi: http://www. doi.org/10.1001/jamasurg.2020.2713.

5. Rosenbaum L. Facing Covid-19 in Italy. Ethics, logistics, and therapeutics on the epidemic's front line. N Engl ] Med. 2020;382(20):1873-5. doi: http://www.doi org/10.1056/NEJMp2005492.

6. Prachand VN, Milner R, Angelos P, Posner MC, Fung J], Agrawal N, et al. Medically necessary, time-sensitive procedures: Scoring system to ethically and efficiently manage resource scarcity and provider risk during the COVID-19 pandemic. ] Am Coll Surg. 2020;231(2):281-8. doi: https://doi.org/10.1016/j.jamcollsurg.2020.04.011

7. Ministerio de Salud y Protección Social. Envejecimiento demográfico en Colombia 19512020. Dinámica demográfica y tendencias poblacionales. Bogotá: Ministerio de Salud y Protección social; 2013.

8. Hewitt ], Carter B, Vilches-Moraga A, Quinn T], Braude $P$, et al. The effect of frailty on survival in patients with COVID-19 (COPE): a multicentre, European, observational cohort study. Lancet Public Health. 2020;5(8): e444-51. doi https://doi.org/10.1016/S2468-2667(20)30146-8.
9. Amblàs-novellas ], Carles ], Molist N, Oller $R$. Índice frágil-VIG: diseño y evaluación de un índice de fragilidad basado en la valoración integral geriátrica. Rev. Esp. Ceriatr Gerontol. 2017;52(3):119-27. doi: https://doi. org/10.1016/j.regg.2016.09.003

10. Menni C, Valdés AM, Freidin $\mathrm{MB}$, Sudre $\mathrm{CH}$ Nguyen LH, Drew DA, et al. Real-time tracking of self-reported symptoms to predict potential COVID-19. Nat Med. 2020;26:1037-40. doi: http://www.doi.org/10.1038/s41591-020-0916-2.

11. Francis N, Dort ], Cho E, Feldman L, Keller $D$, Lim $R$, et al. SAGES and EAES recommendations for minimally invasive surgery during COVID-19 pandemic. Surg Endosc. 2020;34:2327-31. doi: http://www.doi. org/10.1007/s00464-020-07565-w.

12. Tafur Betancourt LA, Zorrilla-Vaca A, Vallejos-Medina LP, Chilatra-Fonseca JM, Angarita-Navarro EC, Martínez-Caviria $M$ et al. Desarrollo del software MyCheckTime ${ }^{\circledR}$ para seguridad perioperatoria con base en la metodología Lean de Toyota. Colombian Journal of Anesthesiology. 2020;48(1):12 9. doi: http://www.doi.org/doi.org/10.1097/ cj9.0000000000000148.

13. Center for Medicare and Medicaid Services. Non-emergent, elective medical services, and treatment recommendations [internet]. 2020 [citado: 2020 nov. 15]. Disponible en: https:// www.cms.gov/files/document/cms-non-emergent-elective-medical-recommendations.pdf.

14. Stahel PF. How to risk-stratify elective surgery during the COVID-19 pandemic? Patient Saf Surg. 2020;14:8. doi: http://www.doi. org/10.1186/s13037-020-00235-9.

15. Royal College of Surgeons of England. Clinical guide to surgical prioritisation during the coronavirus pandemic [internet]. 2020 [citado 2020 nov. 15]. Disponible en: https://www. rcseng.ac.uk/coronavirus/surgical-prioritisation-guidance

16. Mayol ], Fernández Pérez C. Elective surgery after the pandemic: waves beyond the horizon. Br ] Surg. 2020;107(9):1091-3. doi: http:// www.doi.org/10.1002/bjs.11688.

17. Biase G De, Freeman W, Elder B, Nottmeier $E$, Smith $N$, Jerreld $D$, et al. Path to reopening surgery in the COVID-19 pandemic: Neurosurgery experience. Mayo Clin Proc Innov Qual 
Outcomes. 2020;4(5):557-64. doi: http://www. doi.org/10.1016/j.mayocpiqo.2020.06.003.

18. Informe de gestión Nueva EPS. Colombia 2019 [internet]. [citado 2020 nov. 5]. Disponible en: https://nuevaeps.com.co/sites/default/files/inline-files/INFORME \%2ORENDICION \%20DE \%20CUENTAS\%202019.pdf

19. COVID-19 en Colombia: Reporte diario de casos [internet]. 2020 [citado 2020 oct 28]. Dis- ponible en: https://www.ins.gov.co/Noticias/ Paginas/Coronavirus.aspx

20. Aggarwal R, Mytton OT, Greaves F, Vincent C. Technology as applied to patient safety: an overview. Qual Saf Health Care. 2010;19(Suppl 2). doi: http://www.doi.org/10.1136/ qshc.2010.040501.

21. COVID-19 Dashboard by the Center for Systems Science and Engineering (CSSE) at Johns Hopkins University (JHU) [internet] [citado: 2020 oct. 27]. Disponible en: https://gisanddata.maps.arcgis.com/apps/ opsdashboard/index.html\#/bda7594740fd40299423467b48egecf6

22. Bates DW, Gawande AA. Improving safety with information technology. N Engl ] Med. 2003:348(25):2526-34. doi: http://www.doi. org/10.1056/NE]Msa020847. 